\title{
FORMAÇÃO INICIAL DE PROFESSORES DE BIOLOGIA: O ESTÁGIO SUPERVISIONADO COMO MOMENTO DE REFLEXÃO SOBRE A PRÁTICA
}

\author{
Initial training of teachers of biology: the internship supervised as a reflection moment on \\ practice
}

Isabel Cristina Higino Santana - Universidade Estadual do Ceará/Brasil Francisco Alves Santos - Universidade Estadual do Ceará/Brasil Andréa Pereira Silveira - Universidade Estadual do Ceará/Brasil

RESUMO: O estágio supervisionado ainda representa o principal meio de acesso aos conhecimentos e vivências que perfazem o fazer docente. Assim, é por natureza, um ambiente fecundo para a discussão e compreensão dos saberes e significados que este propicia a formação de professores. Desse modo, o objetivo deste trabalho foi discutir a importância do estágio supervisionado na formação inicial de professores de Biologia a partir de reflexões acerca das vivências experimentadas em turmas de primeiro ano do ensino médio. A pesquisa caracteriza-se como um estudo qualitativo, com abordagem autobiográfica tendo como sujeito da pesquisa um professor de biologia em formação inicial. O objeto de análise corresponde às memórias e registros feitos em diários de bordos pelo sujeito de pesquisa. A partir da evocação das experiências e sentimentos manifestados durante as práticas de ensino vivenciadas, foi observado que é no ambiente escolar, o espaço em que professores em formação apropriam-se dos saberes e fazeres próprios da docência mediante uma ação reflexiva que contempla a problematização dos dilemas escolares. Neste contexto, possibilita ainda ao professor aprendiz apropriar-se do seu campo de atuação, através da interação do professor em formação com os diferentes sujeitos que compõem a comunidade escolar. É, por tanto, espaço singular para a construção identitária do profissional docente.

Palavras-chave: Ensino de Biologia. Formação de Professores. Prática de Ensino.

ABSTRACT: The supervised internship still represents the main means of access to the knowledge and experiences that make up teaching. Thus, it is by nature, a fruitful environment for discussion and understanding of knowledge and meanings that this facilitates the formation of teachers. Thus, the aim of this paper was to discuss the importance of supervised internship in the initial formation of Biology teachers from reflections on the experiences experienced in first year high school classes. The research is characterized as a qualitative study, with autobiographical approach having as subject of the research a biology teacher in initial formation. The object of analysis corresponds to the memories and records made in border diaries by the research subject. From the evocation of experiences and feelings manifested during the teaching practices lived, it was observed that it is in the school environment, the space in which teachers in training appropriate the knowledge and doings proper to teaching through a reflective action that contemplates the problematization of school dilemmas. In this context, it also enables the apprentice teacher to appropriate his field of action, through the interaction of the teacher in formation with the different subjects that make up the school community. It is, therefore, a unique space for the identity construction of the teaching professional.

Keywords: Teaching of Biology. Teacher Training. Teaching Practice.

Educação, Psicologia e Interfaces, Volume 4, Número 2, p. 22-34, Abril/Junho, 2020.

ISSN: 2594-5343. DOI: 10.37444/issn-2594-5343.v4i2.230 
Formação inicial de professores de biologia: o estágio supervisionado como momento de reflexão sobre a prática

\section{INTRODUÇÃO}

O estágio enquanto atividade formativa dentro dos cursos de Licenciatura constitui-se como uma ação obrigatória para a formação docente, em consonância com as determinações da Lei de Diretrizes e Bases da Educação - LDB (1996) respaldada pela Lei $\mathrm{N}^{\mathrm{o}} 11.788$ de 25 de setembro de 2008 , que determina:

$\S 1^{\circ} \mathrm{O}$ estágio faz parte do projeto pedagógico do curso, além de integrar o itinerário formativo do educando.

$\S 2^{\circ} \mathrm{O}$ estágio visa ao aprendizado de competências próprias da atividade profissional e à contextualização curricular, objetivando o desenvolvimento do educando para a vida cidadã e para o trabalho. (BRASIL, 2008, p. 1).

Neste sentido, as atividades vividas no ambiente escolar colaboram para a familiarização deste profissional com o futuro ambiente de trabalho, incluindo as rotinas e deveres inerentes à profissão. Segundo Sousa, Torres e Carneiro (2016), “[...] o estágio constitui-se como uma possibilidade de articulação entre teoria e prática e de desenvolvimento profissional inerente à docência", (p. 124). Tal prática prima pela conciliação de saberes, científicos e pedagógicos. Na visão de Lima (2008), o estágio representa um momento de identificação com a profissão de professor, enfatizando a necessidade dos diálogos pedagógicos entre os professores formadores e alunos.

Para Prank e Avila (2015), é o momento onde os professores em formação, desenvolvem o pensamento reflexivo, por meio de atividades como, observação, regência e planejamento das suas ações pedagógicas. Nessa perspectiva, Pimenta e Lima (2011), consideram o estágio supervisionado na formação inicial de professores, como o locus de conhecimentos necessários aos processos formativos, fornecendo dessa maneira, embasamento teórico e metodológico para o processo de compreensão da escola, dos sistemas de ensino e das políticas educacionais, permitindo que sejam repensadas e reavaliadas a cultura escolar e os processos educativos vivenciados no seio das instituições de ensino. Em consonância com essas considerações, Valladão (2004) caracteriza o estágio supervisionado

como um momento de análise e apreensão do contexto real, sendo um elemento indissociável do conhecimento teórico. [...] constitui-se como o espaço, por excelência, em que se realiza a união dialética entre a teoria e a prática (VALLADÃO, 2004, p. 4746-4747).

Educação, Psicologia e Interfaces, Volume 4, Número 2, p. 22-34, Abril/Junho, 2020.

ISSN: 2594-5343. DOI: $10.37444 /$ issn-2594-5343.v4i2.230 
Ampliando as ideias anteriores citadas, Silva (2008) convida a pensar o estágio, como atividade articuladora de vertentes que devem permear a formação e atuação docente nos espaços escolares, tais como, ensino e pesquisa; teoria e prática. Conjugar tais vertentes, que por vezes apresentam-se desarticuladas ao longo do processo de formação inicial dos futuros professores, vem ajudar a pensar o estágio como uma etapa de contatos e diálogos entre a universidade e as escolas de educação básica, buscando a promoção do desenvolvimento de competências técnicas, estéticas e políticas, bem como oportunizar novas experiências do saber docente.

Embora as ideias de estágio supervisionado concentrem-se nos propósitos anteriormente expostos, Milanesi (2012), destaca que,

de acordo com a forma como ele é realizado nas escolas e com o grau de envolvimento das pessoas ali presentes pode ser um espaço de construção de novos significados para a atividade profissional docente quanto de reprodução de modelos preestabelecidos (MILANESI, 2012, p. 225).

Outrossim, é importante que haja uma ação conjunta entre todos os envolvidos neste processo, Professor Orientador - Professor Supervisor - Estagiário, para que a vivência se torne significativa e transformadora. Assim, as atividades de estágio têm por excelência, através de acompanhamento e efetivação didática, a função de desenvolver tendências necessárias ao exercício docente, no intuito de promover a familiarização dos licenciandos com o ambiente escolar e com seus afazeres pedagógicos. E, de maneira relevante, oportunizar momentos de construção da identidade docente, mediante reflexões acerca da prática do professor.

Articuladas a essas premissas, proposições de ações, atividades e discussões são oportunizadas vivências pedagógicas através do contato estabelecido entre a universidade e a escola por intermédio dos sujeitos, professor orientador de estágio e o aluno estagiário. No presente artigo foi analisada a importância do estágio supervisionado na formação inicial de professores de Biologia a partir da reflexão sobre as vivências experimentadas em uma disciplina de estágio supervisionado em turmas de primeiro ano de ensino médio.

\section{MATERIAL E MÉTODO}

Educação, Psicologia e Interfaces, Volume 4, Número 2, p. 22-34, Abril/Junho, 2020.

ISSN: 2594-5343. DOI: 10.37444/issn-2594-5343.v4i2.230 
Formação inicial de professores de biologia: o estágio supervisionado como momento de reflexão sobre a prática

Essa investigação de cunho qualitativo teve como modelo de pesquisa, a autobiográfica, pois, considerando-a como aquela que procura trabalhar com a subjetividade, a perspectiva do sujeito em formação e suas particularidades quanto ao processo citado, é o que Veiga e D'Ávila (2008, p. 120) inscrevem no âmbito,

[...] de pesquisas sócio educacionais como uma possibilidade de, a partir da voz dos atores sociais, resgatar a singularidade das histórias narradas por sujeitos históricos, socioculturalmente situados, garantindo às mesmas o seu papel de construtores da história individual/coletiva intermediada por suas vozes. [...].

A fim de compreender e discutir a importância do estágio supervisionado na formação inicial de professores de biologia, através de atividades e vivências no ambiente escolar, empregou-se como instrumento, o relato de experiências. Os dados coletados são frutos da análise dos diários de bordo construídos durante os períodos de observação e execução das aulas de estágio. Tal instrumento de registros é para Castro et al. (2011, p. 6.) algo que, "[...] vai além de um caderno de anotações ou relatos de casos. Ele contempla a análise sistemática das aulas, críticas, hipóteses de soluções, além de ser um espaço onde se podem expor as emoções pessoais de cada momento".

É, por meio desse instrumento, o diário de bordo, que o sujeito em formação pode refletir acerca de suas experiências, analisando momentos, situações, tomada de decisões, mediante o processo de reflexão sobre a ação, abrindo espaço para novas possibilidades de interpretação de sua ação pedagógica, e, aprimoramento da prática docente, que o constituirão como docente. Dessa forma, configuram-se como fontes ricas de consultas para esse sujeito em formação.

Quanto à pesquisa autobiográfica, sua adoção parte da necessidade em compreender o sujeito como um ser histórico e social, e, por conseguinte, entender sua constituição através da interação com os demais sujeitos, onde se percebe um movimento contínuo entre trocas de experiências e aprendizagens. Representando assim, um constante (re)pensar sobre as ações executadas, além de ampliar as questões teórico-metodológicas da pesquisa. Para o processo formativo de professores, representa oportunidade aos sujeitos de perceberem-se no ambiente, e refletirem sobre suas práticas.

Educação, Psicologia e Interfaces, Volume 4, Número 2, p. 22-34, Abril/Junho, 2020.

ISSN: 2594-5343. DOI: $10.37444 /$ issn-2594-5343.v4i2.230 
As narrativas apresentadas possibilitam ainda a compreensão dos cenários educacionais nos quais estão inseridos, e os sentidos despertados nessas vivências. O entendimento dessas questões oportuniza a identificação de saberes, mobilizados através das experiências, favorecendo deste modo, para professores formadores e em formação, o entendimento de aspectos essenciais desta etapa formativa.

As atividades de observações e regências sobre a qual narramos e refletimos a seguir, foram realizadas no período de março a outubro de 2016, em uma escola de educação básica do município de Itapipoca, região norte do estado do Ceará. Sendo acompanhadas quatro turmas de primeiro ano do ensino médio.

\section{RESULTADOS E DISCUSSÃO}

As atividades docentes estão entremeadas por relações complexas que envolvem poder, conhecimento e transformações. Entender estas questões representa mergulhar em um universo de singularidades, que é o ambiente escolar. Tal complexidade de relações está na heterogeneidade e particularidade dos diversos sujeitos que compõem e dão vida a essa instituição.

Mediante toda essa trama, se faz necessário ao professor em formação, compreender seu papel e suas responsabilidades dentro deste espaço uma vez que este se encontra em um momento de apropriação dos saberes e fazeres da profissão. Por isso, as atividades do estágio curricular obrigatório buscam oportunizar a inserção desse sujeito nos espaços escolares, bem como, proporcionar a execução de tarefas e a reflexão acerca da experiência docente.

Partindo das reflexões oriundas da vivência no Estágio Supervisionado no Ensino Médio I- disciplina curricular obrigatória do curso de Licenciatura em Ciências Biológica da Faculdade de Educação de Itapipoca (PPP, 2011) ${ }^{1}$, algumas problemáticas associadas ao ensino de Biologia são perceptíveis, tais como, redução da carga horária destinada ao ensino de biologia, dificuldades de leitura e interpretação, assim como, a nomenclatura científica.

Os registros dessas questões foram obtidos mediante uma das etapas de realização do estágio, a observação. Esta tem como principal objetivo, colocar o estagiário no papel de espectador dos processos que acontecem dentro da sala de aula, como as estratégias e metodologias aplicadas pelo professor, posturas e atitudes, além

Educação, Psicologia e Interfaces, Volume 4, Número 2, p. 22-34, Abril/Junho, 2020. 
Formação inicial de professores de biologia: o estágio supervisionado como momento de reflexão sobre a prática

das relações que são estabelecidas. E, principalmente, como tudo isso interfere (ou não!) no processo de ensino e aprendizagem. Nas aulas ministradas pelo professor de biologia com turmas de primeira série do ensino médio, e observadas pelo estagiário, foi possível destacar algumas limitações em sala.

Entre essas limitações, foram evidenciadas, aquelas associadas ao caráter formativo, posto a percepção de certo entrave quando eram trabalhados os conhecimentos que envolviam a necessidade de articulações com temáticas referidas ao domínio de conhecimentos na área de Química (por exemplo), trazidos pelos alunos, em especial, aqueles de etapas formativas anteriores. A observação destas questões durante as práticas de estágio supervisionado segundo Souza e Chapani (2018), é comum gerar entre os licenciandos o esmorecimento quanto ao exercício da profissão, no entanto, práticas inovadoras que conciliem experiências complementares de formação de professores tendem a estimular seu processo formativo.

Outro aspecto limitante, diz respeito à ausência de motivação e controle para a indisciplina dos alunos. De acordo com Vasconcelos (2009), estas questões são importantes fatores que interferem diretamente na crise do vínculo do aluno com a escola. Refletir e compreender o processo de apoderamento do espaço escolar enquanto licenciando, representa o entender acerca de sua imersão em uma nova cultura, com valores e costumes próprios. Ações que resultam no desenvolvimento de novas percepções quanto aos espaços físicos no âmbito da educação, rotinas de trabalho, aspectos morais e éticos que norteiam essas vivências, delineando assim, um espaço transitório entre os agentes da escola.

A alocação do licenciando nesta área de aprestamento que é o estágio, favorece o aprimoramento de sua prática e a releitura de concepções prévias sobre sua atuação e relação com os processos de construção idenitária. Por meio dela, o docente em formação inicial pode apaixonar-se e, efetivamente exercer a docência, momento no qual ele assume a sala de aula e, com ela, as responsabilidades e compromissos com a aprendizagem de seus alunos, pressupondo o desenvolvimento de inquietações acerca de suas atitudes e ações. Envolvendo, portanto, um movimento de reflexão sobre suas posturas. Tal reflexão é um ato contínuo e necessário ao professor, pois, através da docência, como afirma Camargo (1983, p.43) é possível “[...] fundamentar os 
licenciandos fazendo-os conhecer e refletir criticamente sobre, os elementos presentes numa situação de ensino e aprendizagem”.

Viver a sala de aula, é sempre uma ação desafiadora e instiga o licenciando, levando-o a confrontar e refletir sobre a realidade escolar, incluindo os aspectos teóricos e práticos da formação docente. Para Veiga (2009), “é preciso entender que a escola não é mais um espaço só de ensino. O que ela de fato procura é estabelecer um elo de aproximação cada vez mais próximo do aluno com a realidade que o cerca" (VEIGA, 2009, p. 15). Esse enfrentamento pode favorecer na compreensão dos sentimentos manifestados durante as experiências na sala de aula, atribuindo desta forma novos sentidos as vivências concretizadas na escola. A imersão do sujeito neste contexto mobiliza inicialmente os saberes experienciais, pelos quais ganham destaque suas histórias de vidas e vivências como alunos fornecendo subsídios que ajudam a reconhecer as individualidades dos sujeitos e do grupo, (QUADROS; KOCHHANN, 2018).

Experienciar as atividades de regências, permitiu perceber que a metodologia de ensino mais comum - a aula expositiva -, não representa necessariamente um modelo tradicional de ensino, desde que haja o reconhecimento e o respeito aos diferentes tipos de saberes apresentados pelos sujeitos da aprendizagem. A composição da identidade profissional para Iza et al. (2014), é representada por uma ação continuada pela qual inicia-se em sua socialização primária, enquanto aluno da escola, seguida pelas ações formativas da licenciatura, até torna-se professor, condição na qual continua em formação permanente. Na visão de Mendes (2005, p. 37,38),

Para desempenhar bem a tarefa complexa de ser professor e de ensinar, é necessário preparo científico (acadêmico e pedagógico) técnico, humano, político-social e ético, suporte do compromisso de intelectual pesquisador, envolvido com as causas democráticas que estimulam a responsabilidade com a formação do homem-cidadãoprofissional.

São ações que precisam estar coadunadas entre teoria e prática, no efetivo exercício da docência, como afirma Vasconcellos (2009), uma ação continuada de formação, que representa uma exigência profissional.

Partindo da premissa de que os sujeitos constroem seus conhecimentos mediante a interação social, e que estes emergem de uma cultura própria e com características 
Formação inicial de professores de biologia: o estágio supervisionado como momento de reflexão sobre a prática

típicas, o desenvolvimento das aulas foram pensados partindo do diálogo entre alunos e professor. A relação dialógica foi considerada essencial ao processo de construção do conhecimento, pois as Ciências Biológicas se apresentam como uma Ciência multidisciplinar e seus diversos campos se relacionam de forma diferente entre os sujeitos e seus costumes, sendo então necessário compreender, como estes saberes escolares se relacionam com o cotidiano dos alunos.

Consciente desta multiplicidade de saberes possíveis, e da necessidade de provocar o confronto entre os saberes escolares, durante as aulas, procurou-se sempre relacionar os saberes científicos ao cotidiano dos alunos, a fim de facilitar a compreensão e a significação desses no contexto real, tornando este saber incorporado, portanto, efetivando o aprendizado.

Esta perspectiva de ensino encontra referências no construtivismo defendido por Vygotsky (1998) ao considerar a aprendizagem, resultado de um processo de interação entre os significados trazidos por seus alunos, e, os culturalmente compartilhados entre os sujeitos. Todavia, buscou-se a promoção de uma aprendizagem significativa, como proposta por Ausubel, e, que, conforme Moreira e Masini (1982, p. 7), “ocorre quando a nova informação ancora-se em conceitos relevantes preexistente na estrutura cognitiva de quem aprende".

É também, foco desse movimento, estabelecer relações com outros temas do universo da formação docente, como questões envolvendo estratégias e metodologias, questões de escrita, modelos didáticos, entre outros. Pozzo em seu texto sobre aprendizes e mestres (2002, p.90), aborda essa questão e diz ser uma busca pelos professores, a respeito de “[...] 'alternativas didáticas', o Santo Graal da aprendizagem”, em que se busca o método que assegure o aprendizado dos conteúdos necessários a formação do aluno.

Nessa mesma linha de pensamento, Paulo Freire (2001, p.266) afirma que, "Por isso mesmo é que estudar é uma preparação para conhecer, é um exercício paciente e impaciente de quem, não pretendendo tudo de uma vez, luta para fazer a vez de conhecer".

Embora a vivência tenha sido em um intervalo semestral, foi possível identificar a importância e relevância das atividades de estágio supervisionado - específica para o ensino médio I, nesta pesquisa, percebendo-se o momento oportuno para o

Educação, Psicologia e Interfaces, Volume 4, Número 2, p. 22-34, Abril/Junho, 2020.

ISSN: 2594-5343. DOI: $10.37444 /$ issn-2594-5343.v4i2.230 
reconhecimento e apropriação da escola enquanto espaço de atuação e transformação social. Outrossim, foi reconhecido tal espaço como de enfretamento para as muitas realidades que constituem o espaço escolar e seus sujeitos. Uma das possibilidades de se reconhecer enquanto formador envolve na concepção de Lucena (2008, p.200) "Os processos de identificação com a profissão docente podem acontecer por meio das atividades realizadas por formadores e formandos".

$\mathrm{O}$ ato de ensinar deve ser entendido pelo estagiário como apenas um dos processos que constitui o ser e estar professor. É importante entender que é na escola que esse constituir-se professor, se torna mais rico e reforça a percepção dos alunos quanto ao "escrito e o vivido" (LUCENA, 2008, p.202). Pois contribui para o enfrentamento nas tarefas de ensinar e aprender, como cita Paulo freire "[...] quem ensina aprende ao ensinar e quem aprende ensina ao aprender (1996, p.25)", e ainda, nas experiências relacionadas aos aspectos pedagógicos, sociais e políticos que favorecem a formação crítica do cidadão.

\section{CONSIDERAÇÕES FINAIS}

As vivências e reflexões de estágio aqui relatadas configuraram-se, principalmente, como momentos de reflexão, compreensão e aprendizado das habilidades necessárias ao exercício docente. Uma vez que corresponde a uma disciplina teórico-prática, articuladora dos saberes necessários ao fazer docente, e possibilita ao licenciando enfrentamento e apropriação do seu campo de atuação, através da interação com os diversos segmentos que compõem o espaço escolar.

A partir desta interação, experiências como, transformação social, política, ética, moral e estética são oportunizadas de modo que o estagiário possa dimensionar a realidade vivida no seio da escola, convidando-o a explorar e descobrir cada vez mais, o mundo de possibilidades para a sua atuação enquanto agente de modificação social.

As condições para que essas transformações ocorram surgem de conexões construídas durante as atividades no ambiente escolar, e com a participação e mediação do professor supervisor, que atua como co-formador, além de estar voltado para sua própria formação continuada. É esse profissional que irá auxiliar o licenciando, ajudando a pensar e (re)significar o seu papel e importância no processo de formação inicial.

Educação, Psicologia e Interfaces, Volume 4, Número 2, p. 22-34, Abril/Junho, 2020. 
Formação inicial de professores de biologia: o estágio supervisionado como momento de reflexão sobre a prática

Este período representa um momento para pensar a sala de aula, suas problemáticas, seus recursos e sentidos como ponto de partida para aprimorar a prática mediante o reconhecimento dos limites e possiblidades que este espaço tem a oferecer ao professor em formação inicial.

Outro destaque diz respeito à vivência diferenciada com, o modelo dialógico adotado. Este permitiu maior liberdade na apresentação e avaliação das diferentes ações realizadas, tornando-as mais significativas e simples, em consequência do caráter informal que apresentam.

Por fim, atividades como observação, planejamento e regências surgem como etapas de experimentação e aprimoramento das ações docentes, pois figuram como mote ao questionamento e que estimulam o uso de inovação metodológica do trabalho docente.

Portanto, a vivência destas atividades representam espaços de construção da identidade docente, onde "verdades" e "mitos" são postos, questionados, refutados, desmistificados e aceitos. Novas formas de pensar e fazer o ensino dentro e fora da sala de aula são discutidos, analisados e (re)estruturados, possibilitando a formação de um perfil docente mais contextualizado com o mundo, com a globalização, com a educação.

\section{Notas de rodapé}

${ }^{1}$ Documento que apresenta uma proposta curricular com objetivo de contemplar ao licenciado uma formação básica, pedagógica e específica na área do ensino de Ciências e Biologia.

\section{REFERÊNCIAS BIBLIOGRÁFICAS}

AUSUBEL, D. P. Psicología educativa. Un punto de vista cognoscitivo. Ed. Trillas. México, 1976.

BRASIL. Lei de diretrizes e bases da educação nacional: Lei no 9.394, de 20 de dezembro de 1996. 11. ed. Brasília: Câmara dos Deputados, 2015.

CAMARGO, D. A. F. A Didática nos cursos de formação de professores: um enfoque piegetiano, ANDES. São Paulo n. 9, p.43-6, 1985.

CASTRO, A. T.; FELICIONI, F.; TÓDERO, B. M.; ALLAIN, L. R. O processo de formação de professores crítico-reflexivos a partir da utilização de Diários de Bordo no PIBID Biologia da Unifal-MG. In: ENCONTRO NACIONAL DE PESQUISA EM EDUCAÇÃO EM CIÊNCIAS, 8, 2011, Atas... Campinas: ABRAPEC, 2011. p.1-12.

Educação, Psicologia e Interfaces, Volume 4, Número 2, p. 22-34, Abril/Junho, 2020.

ISSN: 2594-5343. DOI: 10.37444/issn-2594-5343.v4i2.230 
Disponível em: <http://www.nutes.ufrj.br/abrapec/viiienpec/resumos/R0183-5.pdf>. Acesso em 24 jul. 2018.

FREIRE, P. Carta de Paulo Freire aos professores Ensinar, aprender: leitura do mundo, leitura da palavra. Estudos avançados, v.15, n.42, 2001.

FREIRE, P. Pedagogia da autonomia. 25 ed. São Paulo: Terra e Paz, 1996.

IZA, D. F. V.; BENITES, L. C.; NETO, L. S.; CYRINO, M.; ANANIAS, E. V.; ARNOSTI, R. P.; NETO, S. S. Identidade docente: as várias faces da constituição do ser professor. Revista Eletrônica de Educação, v. 8, n. 2, p. 273-292, 2014.

LIMA, M. S. L. Reflexões sobre o estágio/ prática de ensino na formação de professores. Rev. Diálogo Educ., Curitiba, v. 8, n. 23, p. 195-205, jan./abr. 2008.

LIMA, M. S. L. Reflexões sobre o estágio/prática de ensino na formação de professores. Revista Diálogo Educacional, v.8, n.23, 2008. p. 195-205.

LUCKESI, C. C. Avaliação da aprendizagem escolar: estudos e preposições. 11 ed. São Paulo: Cortez, 2001. (p.102 a 119)

MILANESI, I. Estágio supervisionado: concepções e práticas em ambientes escolares. Educar em Revista, Curitiba, Brasil, n. 46, p. 209-227, out./dez. 2012. Editora UFPR.

MOREIRA, M. A.; MASINI, E. F. S. Aprendizagem Significativa: a teoria de David Ausubel. São Paulo: Morais, 1982.

PIMENTA, S. G. L.; LIMA, M. S. L. Por que o estágio para que não exerce o magistério: o aprender a profissão. In: Estágio e Docência. São Paulo: Editora Cortez, 2011.

POZZO, J. I. Aprendizes e mestres: a nova cultura da aprendizagem. Porto Alegre: Artmed, 2002.

PRANKE, A.; AVILA; L. T. G. Formação inicial de professores em matemática a distância: o portfólio como instrumento de reflexão nos estágios. Educação em Revista, Marília, v.16, n.2, p. 83-96, Jul./Dez., 2015.

QUADROS, C.V.; KOCHHANN, M. E.R. Contribuições do estágio curricular supervisionado da licenciatura em matemática no processo de construção dos saberes docentes dos estagiários. Revista de Ensino de Ciências e Matemática, v. 9, n.3, p. 106-122, 2018.

SILVA, E. P. Q. Estágio supervisionado: espaço de ter-lugar do olhar e de dar a voz. In. SILVA, L. C.; MIRANDA, M. I.(Orgs.). Estágio supervisionado e prática de ensino: desafios e possibilidades. São Paulo, Junqueira \& Marin, 2008.

SOUSA, R. F.; TORRES, C. M. G.; CARNEIRO, C. C. B. S. Estágio supervisionado como espaço de formação do professor de Química e Biologia: reflexões e desafios. In: DIAS, A. M. I.; MAGALHÃES, E. B.; FERREIRA, G. N. L. (Orgs.). Aprendizagem

Educação, Psicologia e Interfaces, Volume 4, Número 2, p. 22-34, Abril/Junho, 2020. 
Formação inicial de professores de biologia: o estágio supervisionado como momento de reflexão sobre a prática

como Razão do Ensino: por uma diversidade de sentidos. Fortaleza: Imprece, 2016. p. 115-128.

SOUZA, E. C. Auto)biografia, histórias de vida e práticas de formação.

NASCIMENTO, A D.; HETKOWSKI, T. M. (Orgs.). Memória e formação de

professores [online]. Salvador: EDUFBA, 2007. Disponível em: SciELO Books .. (pag.

59)

SOUZA, M. L.; CHAPANI, D. T. Aprendizagem da docência: análise de uma proposta de estágio curricular desenvolvida em articulação com o programa novos talentos -

CAPES. Revista de Ensino de Ciências e Matemática, v. 7, n. 1, p. 102-118, 2016.

VALLADÃO, L. A. Ensinar e aprender a partir do estágio supervisionado: biologia do ensino médio. Revista da SBEnBio, n. 7, p.4746-4747, 2014.

VASCONCELLOS, C. S. Indisciplina e disciplina escolar: fundamentos para o trabalho docente. São Paulo: Cortez, 2009.

VEIGA, I. P. A.; D'ÁVILA, M. C. (Org.). Profissão do docente: novas perspectivas, novos sentidos. Campinas-SP: Papirus, 2008.

VYGOTSKY, L. S. Pensamento e Linguagem. São Paulo: Martins Fontes, 1998.

\section{Credenciais da/os autora/es}

SANTANA, Isabel Cristina Higino. Professora da Universidade Estadual do Ceará, Graduada em Biologia (UFC), Mestre em Ciências Marinhas Tropicais (UFC), Doutora em Educação Brasileira (UFC). E-mail: isabel.higino@uece.br

SANTOS, Francisco Alves. Graduado em Biologia (UECE-FACEDI); Especialista em Docência em Biologia e Práticas Pedagógicas (FUNIP). E-mail: falvesantos11@gmail.com

SILVEIRA, Andréa Pereira. Professora da Universidade Estadual do Ceará, Graduada em Biologia (UFC), Mestre em Botânica (UFRPE), Doutora em Ecologia e Recursos Naturais (UFC). E-mail: andrea.silveira@uece.br

Endereço para correspondência: Raimundo Antero, n. 353, Flores 62540-000, Amontada/Ceará. E-mail: falvesantos11@gmail.com

Como citar este artigo (Formato ABNT): SANTANA, Isabel Cristina Higino; SANTOS, Francisco Alves; SILVEIRA, Andréa Pereira. Formação inicial de professores de biologia: o estágio supervisionado como momento de reflexão sobre a prática. Educação, Psicologia e Interfaces, v. 4, n.2, p. 22-34, 2020. Doi: 10.37444/issn-2594-5343.v4i2.230

Recebido: 17/01/2020.

Aceito: 10/03/2019.

Educação, Psicologia e Interfaces, Volume 4, Número 2, p. 22-34, Abril/Junho, 2020.

ISSN: 2594-5343. DOI: 10.37444/issn-2594-5343.v4i2.230 